$$
3<m-m 4-77-70-0002
$$

\title{
Safe TRU Waste Transport System
}

\author{
Prepared by: D. A. Edling \\ Submitted by: K. V. Gilbert \\ Approved by: W. T. Cave
}

October 31, 1977

\section{MONSANTO RESEARCH CORPORATION}

A Subsidiary of Monsanto Company

\section{MOUND IABORATORY}

Miamisburg, Ohio

45342

operated for

\section{UNITED STATES ENERGY RESEARCH AND DEVELOPMENT ADMINISTRATION}

U. S. Government Contract No. EY-76-C-04-0053

\section{DISCLAIMER}

\begin{abstract}
This report was prepared as an account of work sponsored by an agency of the United States Government. Neither the United States Government nor any agency thereof, nor any of their employees, makes any warranty, express or implied, or assumes any legal liability or responsibility for the accuracy, completeness, or usefulness of any information, apparatus, product, or process disclosed, or represents that its use would not infringe privately owned rights. Reference herein to any specific commercial product, process, or service by trade name, trademark, manufacturer, or otherwise does not necessarily constitute or imply its endorsement, recommendation, or favoring by the United States Government or any agency thereof. The views and opinions of authors expressed herein do not necessarily state or reflect those of the United States Government or any agency thereof.
\end{abstract}


PROGKAH AID EUDGET PROPOSAL

OPERATIHC COSTS A:D EQUIPAE:TT 189c No.

AL-6819a

DATE:

October 31,1977

Division of WPR

\section{PROJECT TITLE}

Safe TRU Waste Transport System

\section{SITE Mound Facility}

4. FPF.QUTENCI OF PROGRESS REPORTINQ $\square$ Eonthly $\quad \forall$ semi annual

$\square$ quarterly $\square$ annual

6. CONTRACTOR

Monsanto Research Corp.

7. WONKIHG 1.0CATION

Miamisburg, Ohio

9. TTE
1. Initst:y
2. FRES Lis
3. Fducational
4. Goverriment.
5. Other Mon-Profit

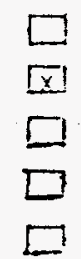

21. 3ㄴ YE.SS

Scientific

2L. costotal Direct

a) Direct Salarics

b) Naterials s Services

c) Subcortrazts

Total biret Costs

d) Indirect cósts

e) Fee

Total Costs (in thousands)

Budget OutTay

Budget Authority

24. EQLIIP:ENT

a) Budget Activily No.

b) EQUIPIEAT OHL.MMITIC NS (ju housands:
5. PERSOII IN CIIARGE

PRINCIPAL IIVESTIGATOR(S)

15. LEAD BRANCH DWPR

EY-76-C-04-0053
12. WASTE APLLICATIO:

$\begin{array}{ll}\text { ERDA } & \square \\ \text { Industry: }\end{array}$

13. TYPE OF $\because 4 S T E$

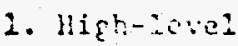

2. Soliding

3. Solici-rission

4.. Tritiun

5. Gaseous or Airborne

6. Othor

FY 1978

ase I Phase II Phase I Phase II Phase I Phase II

1. Open

$[x]$

Lrom

To $\frac{(\text { date })}{(\text { Late) }}$

$$
\text { (date) }
$$

Refércnco: 0.8

8.5 0.5

22.7

12.8

0.2

13.6

0.0

60.0

22.9

86.4

15.7

0.0

38.6

38.6

13.3

0.0

99.7

70.3 384.2

0.5 1.5 46.1

4.0

20.0

8.25 5.25

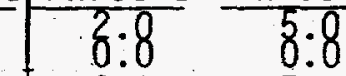

\begin{tabular}{l|ll}
146.9 & 69.6 & 154.9
\end{tabular}

125.9

4.9

25.0 722.8

99.5

124.3

500.0

779

138.5

25.0

137.4

31.0

0.0

95.7

95.1

854.2

0.0

875.3

130.5

134:8

917.7

प्रा7.7

948.3 


\section{INTRODUCTION}

TRANSPORTATION: The transportation of DOE's TRU waste is highlighted in the Defense Waste Program Management Document as one of six key elements in the effective management of TRU waste. In addition, the report of Dr. Magnus' Committee on Transportation of Nuclear Materials discusses several major needs, such as:

- Lack of shipping container standardization.

- Lack of uniform analytical evaluation techniques in determining package performance with respect to test (performance) criteria.

- Lack of public acceptance and understanding of safety aspects.

o Lack of a functional transportation data base.

These can be summarized by stating that a need exists for an integrated, long-term DOE Tranportation Plan.

It is very important that this DOE Transportation PTan be developed now. Mound Facility, recognizing the long lead times required to develop such transport systems and recognizing the need for an operational STRUT System to support the WIPP's start-up (proof of principal operations in FY-1984-FY-1987) in FY-1984, began such a program last year. In addition to the long lead time and WIPP operational support, there are several more important reasons for starting the transportation study now:

1) The volume of TRU waste is increasing and will continue to increase due to major Decontamination and Decommissioning Operations underway or planned throughout the DOE complex. NOTE: There are greater than 1000 ATMX railcar loads of waste at INEL right now... and 10 ATMX railcars available today for transport of such waste.

2) We may not have until FY-1984 to develop the STRUT System. ATMX railcars (4-5 times cheaper than the next most economical transport mode) are currently under scrutiny and may not be authorized for use even through

FY-1978. A long term answer must be developed soon.

Mound has extensive experience in radioactive material package and transport systems development:

- Designed, modified, prepared SARP and secured DOT and DOE certifications for use of ATMX-500 railcars.

- Designed, tested, prepared SARP and secured Transport Certificates of Compliance for several different shipping containers for use with kilogram quantities of plutonium. 
- Completed DOE Funded Program to test and certify Type A Packaging for all of DOE and industry. This document has become the authoritative source for Type A quantity shippers throughout the U.S.

- Currently Mound is developing the design specifications for a standard TRU package for DOE's TRU waste. This program is an excellent opportunity to maximize the obviously needed integration between the TRU package and the STRUT System.

- Compiled a strong data base on all aspects of TRU waste generation, handling and transportation via the TRU Package Program questionnaire submitted to all contractors and the extensive follow-up program of personal contacts and site visits.

- Mound has developed a strong interface and excellent working relationship with WIPP personnel - both DOE and contractor - as a result of its TRU Package Development Program.

Mound Facility's program is designed to fulfill the critical need for an integrated program to provide a Safe TRU Transport System (STRUTS) for transporting DOE's TRU waste to the WIPP. This Mound Facility program incorporates both the systems analysis studies to provide transport hardware development direction and assure its effective implementation and the actual development of the STRUTS hardware. These are described below:

Phase I: Develop and implement via a Systems Analysis approach, a plan to assure that DOE contractor operational needs (with respect to the transport of TRU waste) are identified and fulfilled to assure effective STRUTS implementation.

Phase II: Provide a Safe TRU Transport System (STRUTS) for DOE waste consistent with the WIPP facility start-up schedule.

\section{Phase I:}

The Systems Analysis portion of the program, analyzing contractor needs and developing a plan for effective implementation of the STRUT system will assure sensitivity to the TRU package being developed by Mound, WIPP criteria, retrievable storage site requirement, contractor needs and Federal and State regulations. The depth to which these systems/logistics studies are planned is demonstrated in Figure 1. 


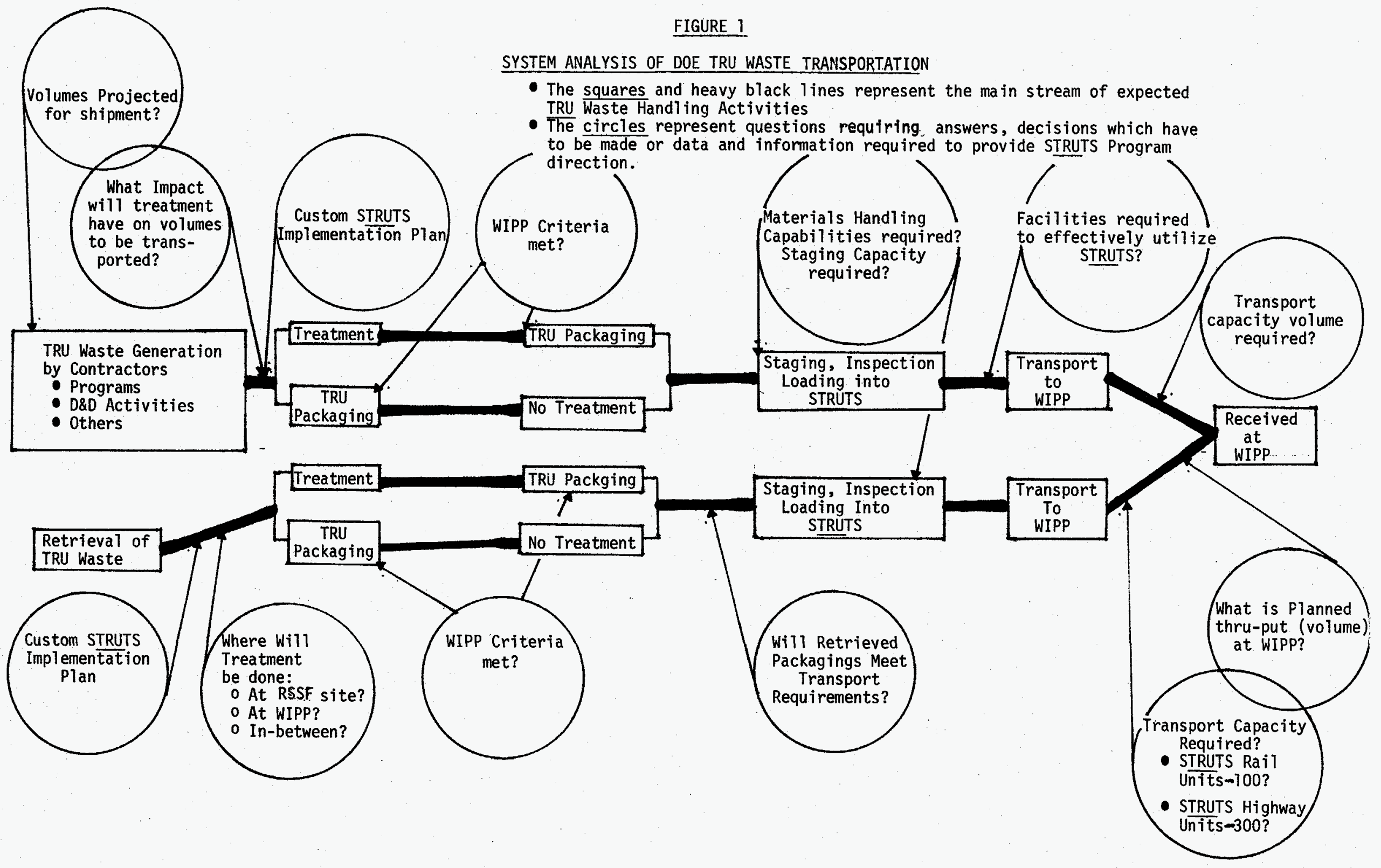


Phase II:

There are currentiy many transport systems used for TRU waste. This program will develop uniform transport system hardware for use by each of the contractor sites. This approach answers the question, "How will DOE's TRU waste be transported in the future?" In addition, it will end the proliferation of TRU transport methods, resulting in enhanced transport safety, cost savings, ease of public acceptance and the benefits mentioned previously.

During FY-1977 Several Major Objectives Were Accomplished:

1) An industrial consultant (Protective Packaging, Inc.) conducted a study and prepared a report on future (4-7 years, hence) transport system requirements.

2) The studies mentioned previously were initiated and preliminary reports prepared discussing such issues have been added to the rapidly growing data base. Such areas as current DOE contractor material handi ing equipment and capabilities, waste staging facilities, transport capabilities, WIPP requirements and waste transport economics are included.

3) Several conceptual STRUT Systems were identified and preliminary evaluations initiated. A wide range of transport economics has been demonstrated from approximately $\$ 14$ per cubic foot for the currently available Super Tiger system to $\$ 3.30$ per cubic foot, which represents an optimum rail transport system.

Transportation is a vital link in the overall Waste Management Program and the STRUTS project will assure a systematic analysis of transport requirements, the development of a uniform transport system and a plan to assure timely and cost effective implementation of STRUTS at the contractor level.

As discussed in previous presentations to DOE/ALO and Headquarters personnel, Mound's plan incorporates all the elements necessary for a successful effort:

1) Full scale performance testing by DOE contractors.

2) Supporting technical analyses, public relations programs, etc. by DOE Headquarters or contractors as appropriate.

3) Total communications and DOE contractor involvement.

4) Effective utilization of industry's technology.

5) Total commitment to meeting contractors" operational needs. 


\section{MILESTONE CHART}

SAFE TRU TRANSPORT SYSTEM DEVELOPMENT OVERVIEW

- Phase I - Systems Analysis

- Phase II - STRUTS Hardware Development

\begin{tabular}{l} 
ACTIVITY \\
\hline Phase I \\
$\begin{array}{l}\text { a) Analyze Contractor Data Bank } \\
\text { o Determine current needs } \\
\text { o Incorporate into STRUTS } \\
\text { design criteria }\end{array}$
\end{tabular}

b) Develop Custom STRUTS

Implementation Plans for each contractor

c) Total Systems Analysis and Integration

0 WIPP

o Retrieval (RSSF's)

- Treatment

o SURF

\section{Phase II}

a) Develop Possible STRUTS Models

b) Industrial Consultant Contract Let

c) Prepare Preliminary Designs

d) Feasibility Analys is of Possible STRUT Systems

o Choose Best One

e) Final Design

f) Fabricate Prototype

g) Test/Analyze to Demonstrate Compliance

h) Prepare SARP and Submit

*Receive Approval

i) Fabricate STRUTS 
During FY-1977 Several Major Objectives Were Accomplished:

1) An industrial consultant (Protective Packaging, Inc.) conducted a study and per the contract prepared a report on future (4-7 years, hence) transport system requirements.

2) Studies have been initiated in areas such as current DOE contractor material handling equipment and capabilities, waste staging facilities, transport capabilities, WIPP requirements, waste transport economics, etc.

3) Several conceptual STRUT Systems were identified and preliminary evaluations initiated.

Our initial objective was to clarify the future TRU waste transport situation. There are several fundamental questions, which when answered, will guide the STRUTS project in the most productive direction. Examples of such questions and answers determined in FY-1977 are:

Question No. 1: Will the rail mode be available for transport of radioactive materials?

Discussion: It appears that the ultimate answer will be yes, rail mode will be available to transport radioactive waste. A recent court decision was made against the railroads' "right" to "flag out" (not carry at al7) radioactive materials. Two pending court cases are expected to reinforce this decision. This isn't the end though. The question of "sole-use train" has not been completely answered. This is important because if "sole-use train" is required, then current economics could make rail transport unattractive with respect to highway transport. This is demonstrated in Table I. As can be seen, the ATMX railcar is four times less expensive than the currently available highway mode (rental of Super Tiger). As long as the "sole-use train" requirement is not imposed, rail offers major economic advantages, but as can be seen, if "sole-use train" is imposed, one has to have an eight-car train (minimum) to offer an economic advantage over highway transport. The cost of individual units, Super Tigers vs. possible rail transport units, require further study, since these data will be critical in this comparison of transport economics. 


\section{TABLE 2}

Transport

Mode

Highway (using Super Tiger)

Current ATMX Railcar

"Sole-Use Train" w/current ATMX Railcar(s)
A) One car train
B) Four car train
C) Eight car train

Cost Per

$\mathrm{ft}^{3}$

$\$ 14.00$

$\$ 3.40$

$\$ 47.00$

$\$ 14.50$

$\$ 8.90$

Question No. 2: What regulatory changes can be expected and what will their impact be?

Discussion: Two major changes have been mentioned:

1) Increased length of thermal test from $0.5 \mathrm{hr}$. current to a possible $1 \mathrm{hr}$.

2) Increase temperature of thermal test from current $800^{\circ} \mathrm{C}$ to $1000^{\circ} \mathrm{C}$.

In addition to present tests, a crush test is expected to be performed. This test is not expected to have a major impact on the STRUT System. The primary impact from the thermal test condition change is expected to be a reduction in volume available for transport utilization. Since the allowed widths for rail and highway are fixed, any increase in the thickness of thermal insulation required will bring a reduction in useful volume. 
Question No. 3: What are the STRUT System/logistics features which will most effective $\overline{l y}$ meet DOE's TRU waste transport needs?

Discussion: An effective STRUT System would most likely include both an approved highway and rail transport mode since not all sites generating waste have a rail siding. A combination of transport modes, e.g., highway to a railcar loading point could prove very practical and economical for small generators. This idea is being pursued.

Phase I (a) Special Analyses Projects WIPP Data Base

Several areas for special emphasis and investigations were identified based on:

1) Heavy MRC involvement in formulation of WIPP Waste Acceptance criteria.

2) Detailed analysis of WIPP Facility Design criteria.

3) Surveillance and personnel contact with OWI, particularly in the area of waste acceptance criteria and the potential impact on WIPP operations.

\section{Rate Study}

Rate changes for the transport of radioactive waste will strongly influence the transport mode chosen. One specific project completed as part of this program was a detailed analysis of the freight rates - how they are determined, the factors of primary influence and an analys is of how these factors will influence the future rates for highway and rail. One conclusion from this study was that neither highway nor rail had a distinct economic advantage since the freight rates for both are expected to increase in a similar manner. This supports our preliminary decision to pursue both highway and rail transport systems.

\section{Contractor Data Base}

A useful data base was established in FY-1977. This was done via analys is of the TRU waste questionnaires employed in MRC's TRU packaging study, visits to each site and the establishment of personal and program contacts at each site and at critical DOE positions. This information has been summarized and documented. This data base will be used to provide preliminary STRUTS hardware development direction and as this data base increases, it will Tead to the site-specific STRUTS implementation plans to be developed beginning in FY-1979. 
Phase II (a) Conceptual Systems

A variety of STRUTS models have been proposed and are in the conceptual design phase. These models include different transport modes, transport systems and packages. Conceptual designs take into consideration site needs, regulations and WIPP capabilities. Special emphasis and interest are being placed on dual purpose systems i.e., systems that work both on rail and highway. This will eliminate potential problems at sites without rail spurs and lower the transport cost for generators of small quantities of waste. Reports discussing these activities have been prepared and distributed quarterly.

\section{EXPECTED RESULTS IN FISCAL YEAR 1978}

The results at this point can be effectively divided into two phases.

Phase I (a) Phase I - TRU Waste Transport Systems Analysis

This systems analysis will

1) Identify the major functions or components in the TRU waste transport chain.

2) Analyze these components and determine the critical path.

3) Develop a detailed plan to achieve the overall objective - the safe and economic transport of TRU waste.

The initial emphasis is on preparing the way for effective implementation, at both the contractor and WIPP operations level, of the STRUTS hardware system. Hardware needs and requirements are being identified based on contractor operations (types of waste, volumes, radiation) and incorporated into the STRUTS design criteria.

Phase II - STRUTS Hardware DeveTopment

Phase II (a) The data base analysis begun in FY-1977 is continuing and is being supported by the TRU waste transport systems analysis begun in midFY-1978. Several conceptual designs postulated in FY-1977 are being

Phase II (b) analyzed. Preliminary designs are being prepared and contractor and WIPP requirements incorporated into the STRUTS System.

It is planned that much of the actual design, testing and analysis and all of the fabrication will be conducted by industry, industrial consultants and/or other DOE contractors. The industrial consultant is being chosen in midPhase II (c) FY-1978 to prepare for contract award in late FY-1978. 


\section{EXPECTED RESULTS IN FISCAL YEAR 1979}

Phase I (b) Phase I: TRU Waste Transport Systems Analys is

Custom STRUTS implementation plans will be developed for DOE contractors (as appropriate) beginning in FY-1979. Individual sites will be analyzed and a TRU waste materials handling model established. Parameters of interest in this detailed analysis include an evaluation of waste staging facilities, railroad interface, materials handling equipment and packaging materials and cost effectiveness.

The objective will be to assure that the implementation of the final STRUTS System is as efficient and cost effective as possible. The site-specific material handling models will point out advance preparations, equipment and facility procurement which must be made. The development of these site models will continue until all sites were completed.

Phase I (c) In addition to these site models, other specific components such as WIPP operational characteristics, retrieval plans at INEL and possible contractor sites, waste treatment plans (and its expected efficiency and effect on waste volumes), SURF, commercial spent fuel storage and later possible re-processing plans will be analyzed. Such an analys is will yield data important to the successful implementation of a STRUT System. These data include announcement of required transport capacity and implementation cost. The data will also enable development of an implementation plan and provide direction to STRUTS hardware development.

Phase II

Phase II ( $c$ ) The preliminary design will be completed to the level of detail required to adequately assess the units. Upon completion of the preliminary designs, each of the systems will be anaiyzed and one system determined to best meet DOE's TRU waste transport needs. One tool to be used in making this final choice is the Modal Determination Matrix or MDM. This concept is described below.

After formalizing the conceptual/idea models, one must be chosen for development. The data and information necessary to determine the optimum STRUT System to pursue will be compiled and an analys is begun early in FY-1979. A Modal Determination Matrix (MDM) will be implemented to determine which STRUT System most effectively meets DOE objectives. An outline of the technique is given in Table 2. This method identifies certain features the STRUT System has to have - MUST's. A11 the MUST's have to be met for continued consideration of the model. Next the desirable features are identified. Some will be highly desirable and some desirable, but to a lesser degree. The performance of each of the models, in 
fulfilling these WANTS, will be evaluated relative to each other. Thus, a performance score will result and from the MDM will come a prioritized iist of possible STRUT System in order of most effectively meeting DOE requirements.

From the MDM a ranking or first assessment could be made of the most promising STRUT System to pursue. The MDM is but one tool which will be used in making the determination of the final STRUT configuration.

\section{TABLE 2}

The Modal Determination Matrix (MDM) For Analyzing Proposed STRUT Systems

Conceptua 1 Models

One Optimum Model To Be Chosen

Model Number

$1 \quad \underline{2} \quad \underline{3} \quad \underline{4}$

Musts

- Capable of meeting regulatory requirements

Yes

No

Yes

Yes

- Meet WIPP criteria

Yes

Yes

Yes

Yes

Go

No Go

Go

Go

Wants

- Compatibility with existing TRU packagings

80

70

40

40

- Economic Transport Rates

90

50

20

20

Total

700

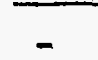

550

400 
32. EXPECTED RESULTS IN FISCAL YEAR 1980

\section{Phase I - Systems Analyses}

Phase I (b) Preparation of the custom implementation plans for each site will continue along with the total Systems Analysis begun in FY-1979. By this time much more definitive information will be available to provide final program direction.

\section{Phase II - STRUTS Hardware}

The final, optimum STRUT System was determined using the MDM approach in FY-1979. In FY-1980, the final design of this system will be established and blueprinted. At mid-year the fabrication of the prototype system will begin. These prototpyes will be completed in FY-1981, the testing and analyses portion completed in FY-1982, the SARP approved in FY-1983 and the initial STRUT Systems fabricated in FY-1984 to support WIPP targeted start-up. 